\title{
A stretchable inertial microfluidic device for tunable particle separation
}

\author{
Hedieh Fallahi, Jun Zhang, Jordan Nicholls, Hoang-Phuong Phan and Nam-Trung Nguyen * \\ Queensland Micro and Nanotechnology Centre, Griffith University, Brisbane, QLD 4111, \\ Australia \\ * Correspondence: nam-trung.nguyen@griffith.edu.au; Tel: +61-(07)-3735-3921; Fax: +61-
}

(07)-3735-80211

\begin{abstract}
Inertial microfluidics is a promising approach for particle separation due to the superior advantages of high throughput, simplicity, precise manipulation and low cost. However, the current obstacle of inertial microfluidics in biological applications is the broad size distribution of biological microparticles. Most devices only work well for a narrow range of particle sizes. For focusing and separating a new set of particles, troublesome and time-consuming design, fabrication, testing and optimization procedures are needed. As such, it is of particular interest to design a microfluidic device that can be tuned and adjusted to separate particles of various sizes. This paper reports on the proof of concept for a stretchable microfluidic device that can control the length via a stretching platform. By changing the channel dimensions, the device can be adapted to different particle sizes and flow rate ratios. We successfully demonstrate this approach with the separation of a mixture of 10 and $15-\mu \mathrm{m}$ particles. Stretching the device significantly improves the focusing and separation efficiency of the specific particle sizes. We also show that there is an optimum stretch length, which results in the best separation performance. The proof of concept reported here is the first step towards designing stretchable inertial microfluidic devices that can be implemented for a wide range of biological and medical applications.
\end{abstract}

Key words: stretchable microfluidics, tunable separation, inertial microfluidics

\section{INTRODUCTION}

The use and manipulation of microparticles have quickly emerged across many industries ${ }^{1}$ ranging from the food industry ${ }^{2}$ to water purification ${ }^{3}$ and cosmetics industry ${ }^{4}$. There is a great demand for systems that can focus, sort, and separate microparticles of various types. More importantly, biomedical ${ }^{5}$ and biological ${ }^{6}$ applications demand devices that can sort, focus, purify, and separate biological samples such as cells, blood and tissues, etc. ${ }^{7,8}$. Such a device would allow for rapid and more effective diagnosis and treatment of diseases such as cancer.

Microfluidic technology has become a promising candidate to meet the above demands ${ }^{9}$. Microfluidics manipulates fluids containing suspended particles using channels with dimensions from tens to hundreds of micrometres. The characteristic length scale of microfluidic devices matches that of target microparticles such as cells, providing an unprecedented advantage for precise manipulation and separation at the single-particle level. 
Among microfluidic techniques utilizing active force fields ${ }^{10-17}$ and passive hydrodynamic forces ${ }^{18-22}$ for separating particles, inertial microfluidics is particularly attractive due to their superior features including high throughput, simplicity, precise manipulation, and low cost ${ }^{22-}$ ${ }^{24}$. The parameters affecting the performance of an inertial microfluidic device are the channel geometry, flow rates and flow rate ratios of the fluids, and the outlet resistance ${ }^{25-30}$. Various research groups have extensively explored the way to improve the performance of inertial microfluidic devices. Zhou and Papautsky have investigated several aspects of focusing and sorting in inertial microfluidics for size-based sorting of biological samples including the implementation of multi-flow straight channels ${ }^{31}$, using shear-induced diffusion ${ }^{32-34}$, and tuning the cut-off sizes of the device by manipulating the output resistance ${ }^{26}$ as well as introducing a vortex-aided sorting chamber ${ }^{35}$. Researchers have also explored parameters affecting the performance of inertial microfluidic devices including channel geometry, flow rates and flow rate ratios of the fluid ${ }^{27-30}$. Bogseth et al. investigated the effect of the above parameters on the tunability of a co-flow inertial microfluidic device ${ }^{28}$. Mukherjee et al. introduced a triangular channel cross section for single-stream inertial focusing ${ }^{36}$. Zhang et al. proposed a dielectrophoresis (DEP)-inertial microfluidic device to obtain tunable particle separation $^{37}$. Very recently, Zhou et al. used non-Newtonian viscoelastic fluids for highefficiency tuning of particles separation in a wavy channel ${ }^{38}$.

Although many attempts have been made to achieve a tunable focusing and soring performance, there are still limitations with the current designs. For instance, most devices have a fixed design and cannot be changed after fabrication. Thus, these devices work well only across a limited range of particle sizes. For manipulating and separating a new set of particles that are outside of the design range, repetitive and time-consuming procedures of design, fabrication, testing and optimization are needed. Moreover, for applications where the samples may have a broad range of sizes, multiple channels with various channel dimensions (e.g., lengths or widths) are required ${ }^{28}$.

Very recently, flexible and stretchable microfluidic technology has emerged and is starting to find practical applications. We have provided a comprehensive review of perspectives and also the state of the art of flexible microfluidics ${ }^{39}$. Flexible microfluidics relies on platforms entirely made of flexible materials. In our present trials, we utilise the concept of stretchability for inertial microfluidics by developing a device with a tunable channel length. We show that such a device may pave the way for the new generation of adjustable inertial microfluidics which in turn will have a great impact on separation and sorting applications. The 
channel length of the proposed device can be adjusted precisely in real-time by an external stretching mechanism. First, we conducted a theoretical study to analyse the mechanism of tunable particle focusing and separation by elongating the channel. Second, we designed and fabricated a thin stretchable microfluidic device and the corresponding external stretching platform. Third, to validate our device, we introduced microparticles into this stretchable inertial microfluidic device and analysed the focusing behaviour of microparticles under different stretching lengths. Finally, a mixture of particles was injected into the device to investigate the separation performance of the proposed stretchable device. The results showed that our device can improve the focusing and separation performance by adjusting the channel length and can be used for a broad range of flow rate ratios. We believe that this stretchable inertial microfluidic platform will provide more flexibility and tunability in particle manipulation and separation simply by changing the channel dimension on site and in real time.

\section{THEORY}

\section{Mechanism of inertial migration in an elongating straight channel}

Inertial migration is a phenomenon where randomly dispersed particles at the entrance of a channel migrate laterally to several cross-sectional equilibrium positions after a long enough passage ${ }^{40,41}$. Assuming that the particles are much smaller than the channel dimension, the inertial lift force $F_{L}$ is expressed as ${ }^{22,42}$ :

$$
\begin{aligned}
& F_{L}=f_{L} G^{2} \rho a^{4} \\
& G=2 U_{f} / D_{h} \\
& F_{L}=4 f_{L} U_{f}^{2} \rho a^{4} / D_{h}^{2} \\
& U_{f}=Q /(W H)
\end{aligned}
$$

where $\rho$ is the fluid density and $G$ is the shear rate, $U_{\mathrm{f}}$ is the average flow velocity of fluid, $Q$ is the fluid flow rate, $a$ is the particle diameter, $f_{\mathrm{L}}$ is a non-dimensional lift coefficient for inertial lift force. The hydraulic diameter $D_{\mathrm{h}}$ is defined as $D_{\mathrm{h}}=2 \mathrm{WH} /(\mathrm{W}+H)$ for a rectangular channel ( $W$ and $H$ correspond to the width and height of the rectangular cross section, respectively). 


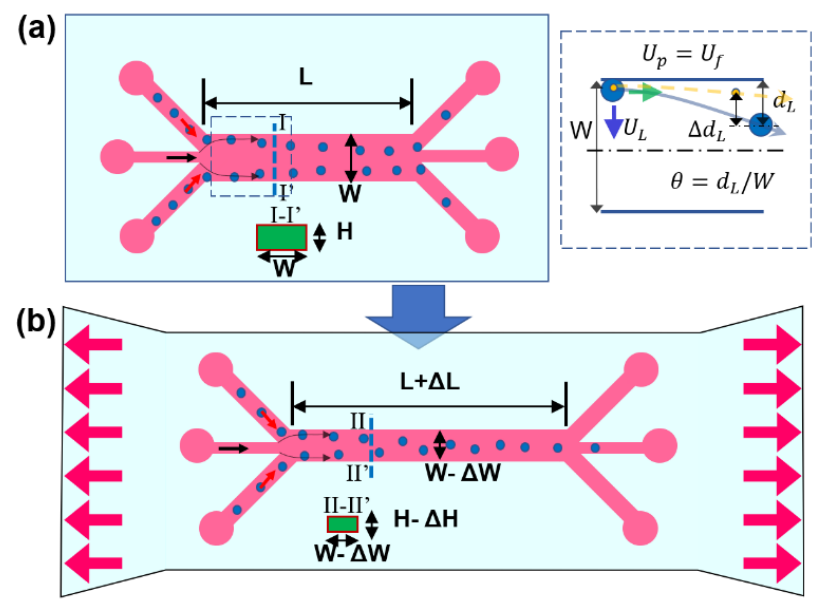

Figure 1. Particle inertial migration to the channel centre in a low-aspect-ratio channel: (a) before and (b) after stretching the channel along the length direction. The inset illustrates the lateral migration of particles.

The lateral migration velocity of particles $U_{\mathrm{L}}$ can then be calculated by balancing the inertial lift with Stokes drag $F_{\mathrm{D}}=3 \mu \pi a U_{\mathrm{L}}$ :

$$
U_{L}=\frac{F_{L}}{3 \pi \mu a}=\frac{4 U_{f}^{2} \rho a^{3} f_{L}}{3 \pi \mu D_{h}^{2}}
$$

The displacement of particles released from the side walls along the lateral direction within the straight channel of length $L$ can be estimated as, Figure 1(a):

$$
d_{L}=U_{L} \frac{L}{U_{f}}=\frac{4 \rho a^{3} L U_{f} f_{L}}{3 \pi \mu D_{h}^{2}}=\frac{\rho a^{3} L Q(W+H)^{2} f_{L}}{3 \pi \mu(W H)^{3}}
$$

The particle migration along the width of a low-aspect-ratio $(\delta=H / W<1)$ channel is dominated by the rotation-induced lift force, and the coefficient $f_{\mathrm{L}}$ scales $\mathrm{as}^{25}$ :

$$
\begin{gathered}
f_{L} \propto \frac{H^{2}}{a \sqrt{R e}} \\
\operatorname{Re}=\frac{\rho U_{f} D_{h}}{\mu}=\frac{2 \rho U_{f} W H}{\mu(W+H)}
\end{gathered}
$$

Substituting Equations $(7,8)$ into Equation (6) results in:

$$
d_{L} \propto \frac{\rho^{\frac{1}{2}} a^{2} L Q^{\frac{1}{2}}(1+\delta)^{\frac{5}{2}}}{\mu^{\frac{1}{2}} W^{\frac{3}{2}} \delta}
$$

As PDMS is isotropic and the Poisson ratio $v$ of PDMS is 0.5 ,

$$
\begin{aligned}
& \frac{\Delta L}{L}=0.5 \frac{\Delta W}{W}=0.5 \frac{\Delta H}{H} \\
& \delta=\frac{H}{W}=\frac{\Delta H}{\Delta W}=\frac{H-\Delta H}{W-\Delta W}
\end{aligned}
$$

The aspect ratio $\delta$ is constant when elongating the channel. Equation (9) can be further simplified as: 


$$
d_{L} \propto \frac{a^{2} L Q^{\frac{1}{2}}}{w^{\frac{3}{2}}}
$$

Elongating the channel length also alters other dimensions of the microchannel along the transversal direction. As such, a lateral displacement ratio, $\theta$, is defined as the ratio of particle lateral displacement to the channel width. Particles reach a complete focusing with $\theta=1 / 2$, since particles migrate laterally forward and will stabilize at the channel centre, Figure 1(b).

$$
\theta=\frac{d_{L}}{W} \propto \frac{a^{2} L Q^{\frac{1}{2}}}{W^{\frac{5}{2}}}
$$

For the same particle diameter, $a$ and under a constant flow rate $Q$, stretching the channel along the length $(L)$ will decrease the channel width $(W)$ and height $(H)$. Therefore, from Equation (13), the lateral migration distance ratio $\theta$ increases, indicating that the particles migrate closer to their final focusing positions after the stretching. Note that $\theta$ cannot be larger than 0.5 , since this is the maximum value representing the focusing state of the particles. Therefore, we can conclude that stretching the channel along the length will facilitate particle inertial migration and focusing.

In terms of particle separation, for a binary particle mixture with particle diameters of $a_{1}$ and $a_{2}$, the difference in lateral displacement ratio $\left(\theta_{1^{-}} \theta_{2}\right)$ is:

$$
\left(\theta_{1}-\theta_{2}\right)=\frac{\Delta d_{L}}{W} \propto \frac{L Q^{\frac{1}{2}}}{W^{\frac{5}{2}}}\left(a_{1}^{2}-a_{2}^{2}\right)
$$

The above scaling relationship infers that stretching the channel length will increase the lateral distance between the binary particles before the large particles arrive at the channel centre $(\theta=1 / 2)$. After the larger particles reach and stabilize at the channel centre, further stretching will adversely decrease the lateral distance of binary particles, which will now be verified through experiments in the following sections. Therefore, the condition for equation (14) is $\left(\theta_{1}, \theta_{2}\right) \leq 1 / 2$.

\section{MATERIALS AND METHODS}

\section{Design and fabrication}

A stretchable microfluidic device was designed and fabricated as illustrated in Figure 2(a,b). The fabrication procedure and design guidelines are elaborated in the supporting information (SI). The microchannel has two inlets; one for the introduction of the sample flow, and one for the sheath flow, Figure 2(a)i. The fabricated straight channels have a width and height of 100 $\mu \mathrm{m}$ and $50 \mu \mathrm{m}$, respectively with two lengths of 5 and $10 \mathrm{~mm}$. We also designed and fabricated a custom-made stretching platform to elongate the PDMS microfluidic device along its length 
direction as schematically illustrated in Figure 2(c,d). More information on the design is provided in SI.

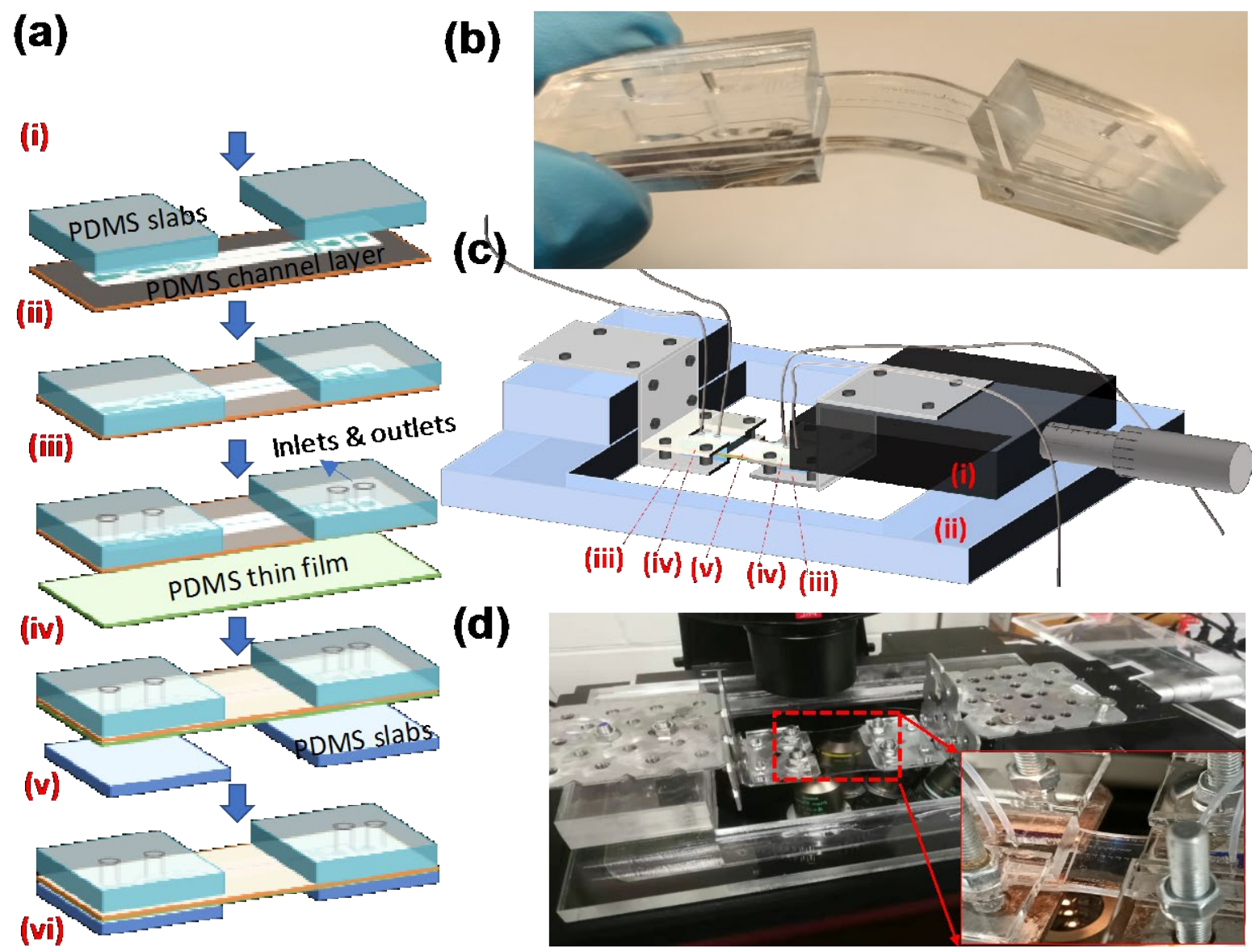

Figure 2. (a) Fabrication steps of the thin stretchable PDMS microfluidic device. (i) The device was fabricated by selectively exposing the SU8 photoresist to UV light. The unexposed SU8 was removed after development; (ii) A thin layer of liquid PDMS mixture was poured on the silicon master and then peeled off; (iii) Two thick PDMS slabs were bonded onto the top of the channel layer covering the areas of inlet and outlet; (iv) The inlet and outlet holes were punched for fluid infusion and collection; (v) A thin PDMS film was bonded to the channel layer after plasma treatment. (vi) Another two bottom PDMS slabs were bonded to the inlet and outlet areas. (b) A photo of a fabricated stretchable PDMS microfluidic device. (c) A schematic illustration of the stretching device and the flexible PDMS microfluidic device. The stretching device is comprised of a micrometre translation stage (i) on top of a PMMA platform (ii). Two metal clamps (iii) attached to either side of the translation stage, the PDMS device (v) was clamped by two PMMA slabs (iv). (d) Photo of a flexible PDMS device clamped in the stretching device. The inset shows a photo of the PDMS microfluidic device under elongation.

\section{Particle preparation}

Polystyrene microspheres with diameters of $10 \mu \mathrm{m}$ (Thermo Fisher Scientific, Product No. G1000, CV5\%) and 15- $\mu \mathrm{m}$ (Phosphorex, Product No. 2228, CV8.31\%) were dispersed in deionized (DI) water with a particle weight ratio of $0.05 \%$ in suspension. Tween 20 (Sigma- 
Aldrich, Product No. P9416) was added to DI water as a surfactant at a weight ratio of $0.5 \%$ $\mathrm{v} / \mathrm{v}$ to avoid particle aggregation and sodium chloride $(\mathrm{NaCl})$ was added at a weight ratio of $7 \%$ to increase the density of the solution to reduce particle settling. For the sheath flow, an aqueous solution with $0.5 \% \mathrm{v} / \mathrm{v}$ Tween 20 and $7 \% \mathrm{w} / \mathrm{w}$ of $\mathrm{NaCl}$ was prepared.

\section{Experimental setup}

The stretching platform with the polydimethylsiloxane (PDMS) device was placed on the stage of an inverted microscope (Nikon, Eclipse TS100), Figure 2(d). A syringe pump (neMESYS, Centoni $\mathrm{GmbH}$ ) with two flow-rate control units delivered a continuous sample flow and sheath flow into the microfluidic device. The flow rate of the sample is $10 \mu 1 / \mathrm{min}$ and the flow rate of sheath flow was varied from $50 \mu \mathrm{l} / \mathrm{min}$ to $215 \mu \mathrm{l} / \mathrm{min}$. A high-speed CCD camera (Phantom Miro3, Vision Research) was mounted on the microscope and recorded videos of the particles in the channel using an exposure time of $30 \mu \mathrm{s}$. Each video has on average 3,000-8,000 frames. The open-source software ImageJ (National Institutes of Health USA) was used to extract quantitative information of the size, distribution and location of the microparticles in the main channel and at the outlet.

\section{RESULTS AND DISCUSSION}

\section{Microfluidic channel deformation under stretching}

We used COMSOL Multiphysics software to study how the dimensions of the microchannel change under stretching. We simulated the deformation of the microfluidic channel at stretching lengths ranging from $0 \mathrm{~mm}$ to $8 \mathrm{~mm}$. More information on COMSOL modelling is provided in the supplementary information. Figure 3(a) illustrates the deformation of the thin PDMS device under a longitudinal stretching. The variation of channel width and height was evaluated at each stretching condition, Figure 3(c). As expected, the width and height of the channel were reduced by increasing the stretching length. This resulted in a decrease in the cross-sectional area. Therefore, for a constant flow rate, the fluid velocity increases reversely to the reduction of the cross-sectional area, Figure 3(b, c). Interestingly, although the channel width and height change with stretching, their aspect ratio $(\delta=H / W)$ remains constant for different stretching lengths, as shown in the inset of Figure 3(c). These results agreed with the above theoretical analysis. 

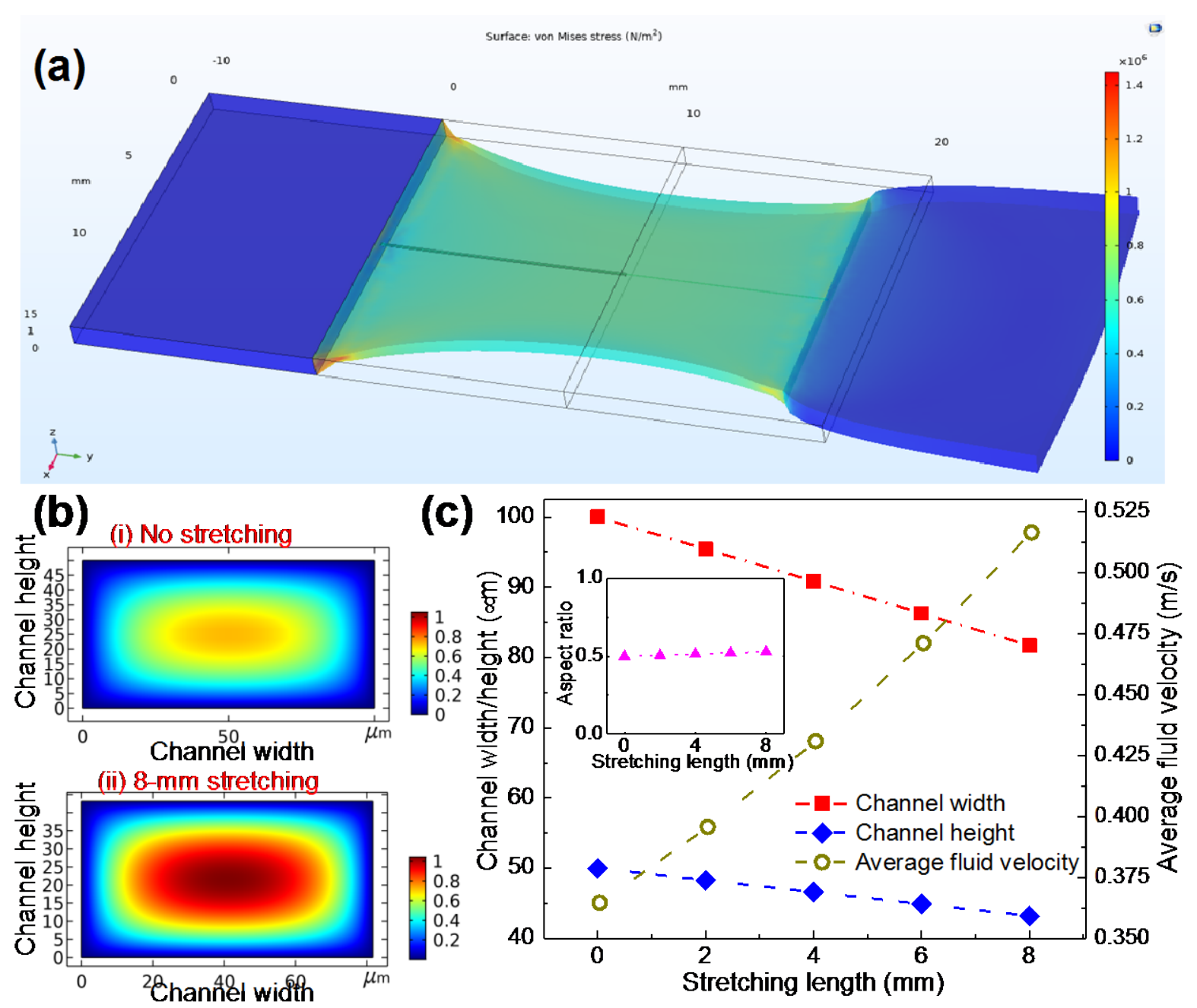

Figure 3. Deformation of the PDMS device and microchannel when stretching is applied along the longitudinal direction. (a) Numerical modelling of deformation of the PDMS device under a longitudinal stretching. (b) The simulated velocity distribution in the channel cross section before and after stretching along the longitudinal direction wit a constant flow rate. The reduction of channel cross-sectional area results in a higher fluid velocity after stretching. (c) The variation of channel width, channel height and average fluid velocity with stretching length ranging from $0 \mathrm{~mm}$ to $8 \mathrm{~mm}$. The insert indicates that the channel aspect ratio $(\mathrm{H} / \mathrm{W})$ remains almost constant as $\sim 0.5$ for different stretching lengths.

\section{Particle focusing in the stretchable inertial microfluidic device}

To evaluate the focusing performance of our stretchable platform, we investigated inertial focusing of particles in the device under different stretching lengths. A straight channel with a length of $10 \mathrm{~mm}$ was selected. The flow rate ratio, defined as the ratio between the flow rates 
of the sample and the sheath flow, was kept constant at $10 \mu \mathrm{l} / \mathrm{min}$ : $50 \mu 1 / \mathrm{min}$. To quantify the device performance, focusing efficiency, defined as the ratio of particle number in the final equilibrium position to the total particle number, was calculated at the end of the channel for each stretching length. ${ }^{43}$ For a straight channel with an aspect ratio $(\mathrm{H} / \mathrm{W})$ of 0.5 , the particle final equilibrium position is at the channel central area. ${ }^{23}$ Hence, particles locating within $5 \mu \mathrm{m}$ of the centre line of the channel were considered as focused and counted for the calculation of focusing efficiency.

Figure 4 illustrates the progression in the particle focusing at the end of the straight channel as the channel is stretched. Without any stretching, merely $28.9 \%$ of particles were focused at the channel central area, while most of the particles were distributed widely across the channel, Figure 4(a). As we stretched the device for $2 \mathrm{~mm}$, Figure 4(b), more particles migrated into the channel centre with a focusing efficiency of $45.03 \%$. By further increasing the stretching length to $4 \mathrm{~mm}, 84.17 \%$ of the particles were focused into the channel centre, Figure 4(c). Finally, at a stretching length of $6 \mathrm{~mm}$, we observed a complete focusing of particles in the channel centre with a focusing efficiency of approximately $100 \%$, Figure 4(d). These experimental results agree well with the theoretical analysis, as equation (13) predicts that stretching the channel length can promote the lateral migration of particles and final focusing. 
(a)
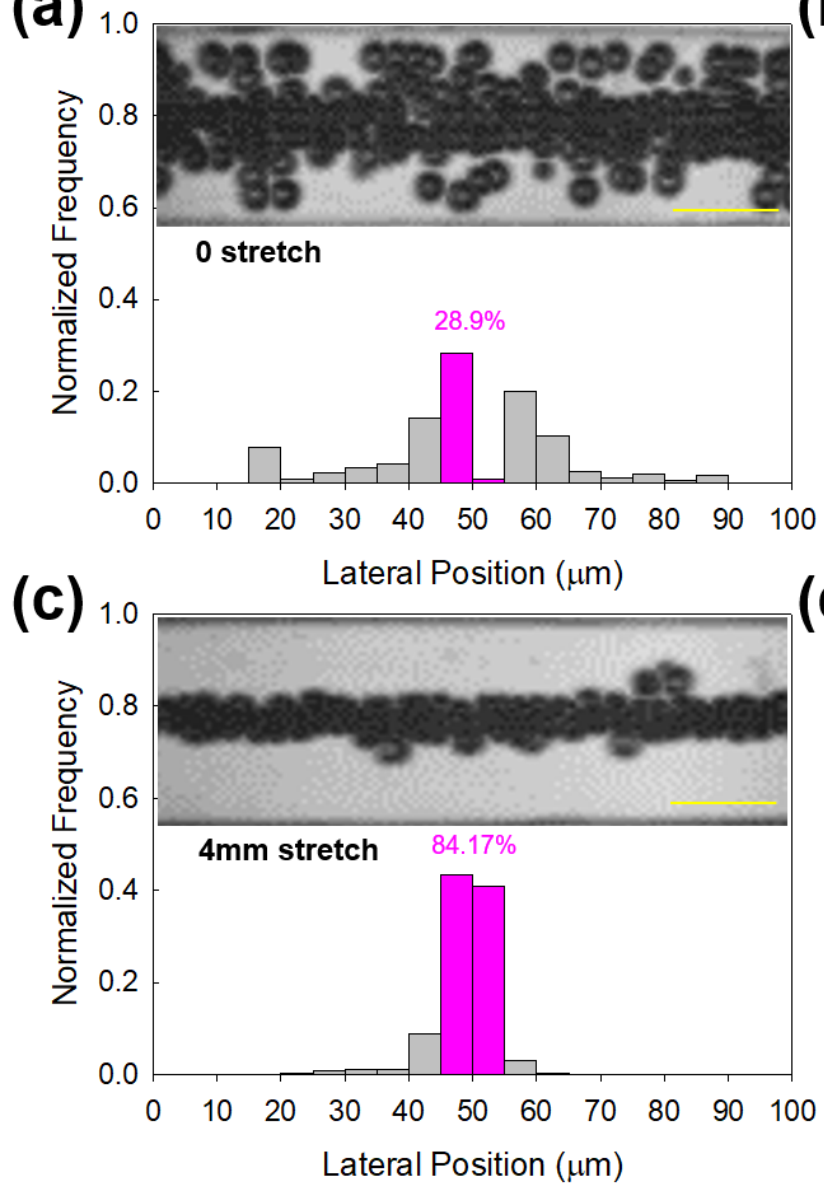

(b)

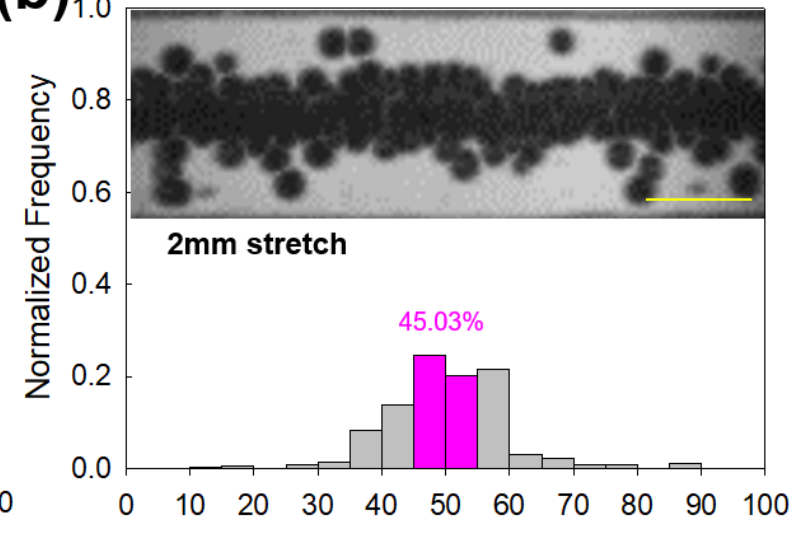

(d)

Lateral Position $(\mu \mathrm{m})$

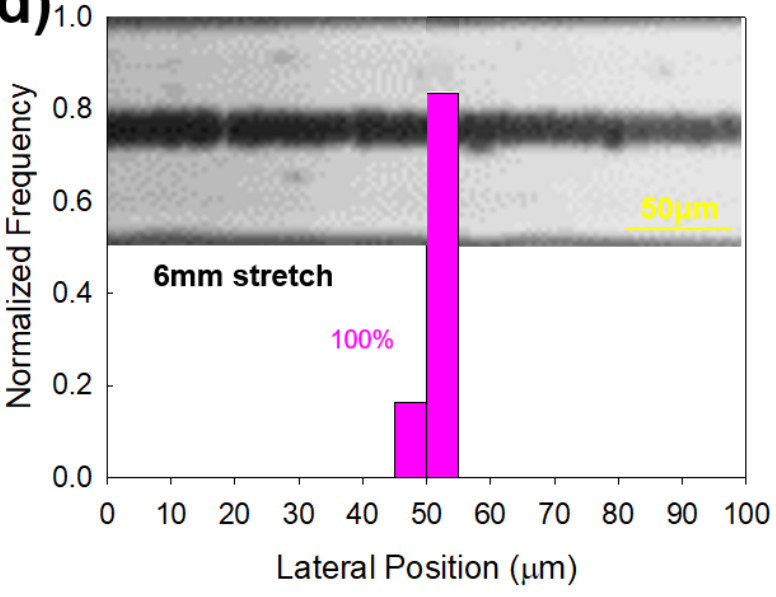

Figure 4. Particle inertial focusing efficiency under different stretching lengths of (a) $0 \mathrm{~mm}$; (b) $2 \mathrm{~mm}$; (c) $4 \mathrm{~mm}$; and (d) $6 \mathrm{~mm}$. The particle diameter is $15 \mu \mathrm{m}$. The length of the straight channel is $10 \mathrm{~mm}$. The flow rates of the sample flow and sheath flow are $10 \mu \mathrm{l} / \mathrm{min}$ and $50 \mu \mathrm{l} / \mathrm{min}$, respectively. The channel width was $100 \mu \mathrm{m}$, and so the centre line is at the lateral position of $50 \mu \mathrm{m}$. The pink bars represent the focused region.

\section{Particle separation in the stretchable inertial microfluidic device}

After demonstrating that a microfluidic device can achieve particle focusing by stretching, we further investigated particle separation in the stretchable device. A suitable channel length is a key parameter in kinetic separation methods, ${ }^{44}$ which depends on the rate of particle deflection perpendicular to the primary flow. The particle inertial differential migration and separation mechanism in the straight channel are provided in the SI. By controlling the channel length via stretching the device, particle separation can be tuned and optimised. We investigated the inertial separation of a binary particle mixture at varying stretching length to evaluate the tunability of the stretchable microfluidic device.

A mixture of $15-\mu \mathrm{m}$ and $10-\mu \mathrm{m}$ particles was introduced to a $5-\mathrm{mm}$ long microchannel. The flow rate ratio of sample flow to sheath flow is $10 \mu \mathrm{l} / \mathrm{min}: 215 \mu \mathrm{l} / \mathrm{min}$. The initial length was selected so that without stretching, particle separation cannot be achieved. Figure 5 (a) 
shows the count of the particle positions at the end of the channel without stretching, and the inset shows a representative image at the end of the microchannel. The particles of neither sizes were focused in the centre. Both particle types are pinched near the sidewalls due to the relatively high sheath flow forcing them to the sidewalls. The $15-\mu \mathrm{m}$ and $10-\mu \mathrm{m}$ particles are still overlapping along with the channel width. The $15-\mu \mathrm{m}$ particles have deflected slightly towards the centre, but not enough to enable an efficient separation, Figure 5(b)i. Successful separation would require a longer channel length so that the $15-\mu \mathrm{m}$ particles, migrating faster than the $10-\mu \mathrm{m}$ particles, have enough time to migrate to the channel centre.

Stretching the channel along the length direction causes the larger $15-\mu \mathrm{m}$ particles to move closer towards the channel centre. Consequently, an increasing percentage of the $15-\mu \mathrm{m}$ particles enter the central outlet, Figure 5(b). Furthermore, by increasing the stretching length, the lateral distance between $15-\mu \mathrm{m}$ and $10-\mu \mathrm{m}$ particle populations increases. When the stretching length is over about $6 \mathrm{~mm}$, the binary particle populations occupy distinct lateral positions and exit from different outlets. Therefore, a complete kinetic separation can be achieved. The observed behaviour agrees well with the scaling relationship of Equation (14) for the difference of lateral displacement ratio $\left(\theta_{1}-\theta_{2}\right) \propto L W^{-2.5}$. Stretching the channel length increases $L$ and decreases $W$, increasing the difference $\left(\theta_{1}-\theta_{2}\right)$. It should be noted that this result will not apply when either of particle population reaches the final equilibrium position, i.e., channel centre. In that case, increasing the stretching length further will reduce the lateral displacement difference.

Two parameters - purity and separation efficiency are defined to quantitatively evaluate the separation performance of the device under different stretching lengths. The purity of a target particle is defined as the ratio of the number of the specific target particles to the total number of particles from a given outlet ${ }^{45}$. The separation efficiency (S.E.) is defined as the ratio of the number of the target particles from a given outlet to the total number of the same particles from the inlet. ${ }^{45}$ Figure 5(c) shows the purities and separation efficiencies at the different stretching lengths. At the original state $(0 \mathrm{~mm}$ elongation $)$, S.E. of $10-\mu \mathrm{m}$ particles is $100 \%$ since no $10-\mu \mathrm{m}$ particle is in the central outlet. S.E. of $15-\mu \mathrm{m}$ particles is $0 \%$ since the desired central outlet for $15-\mu \mathrm{m}$ particles cannot collect any particles. However, all $15-\mu \mathrm{m}$ particles entered the side outlets, and the purity of $10-\mu \mathrm{m}$ particles was poor $(\sim 80 \%)$, which is the same as that of the inlet. By increasing the stretching lengths, the S.E. of $15-\mu \mathrm{m}$ particles increases sharply from $0 \%$ to almost $91 \%$ at $4-\mathrm{mm}$ stretching lengths. When the stretching lengths are above $4 \mathrm{~mm}$, the increment ratio of S.E. becomes much slower, and reaches around 
$100 \%$ at the stretching length of $8 \mathrm{~mm}$. Meanwhile, the purity of $10-\mu \mathrm{m}$ particles increases from $80 \%$ to $97 \%$ with a stretching length of $4 \mathrm{~mm}$ and remains almost the same even with further stretching.

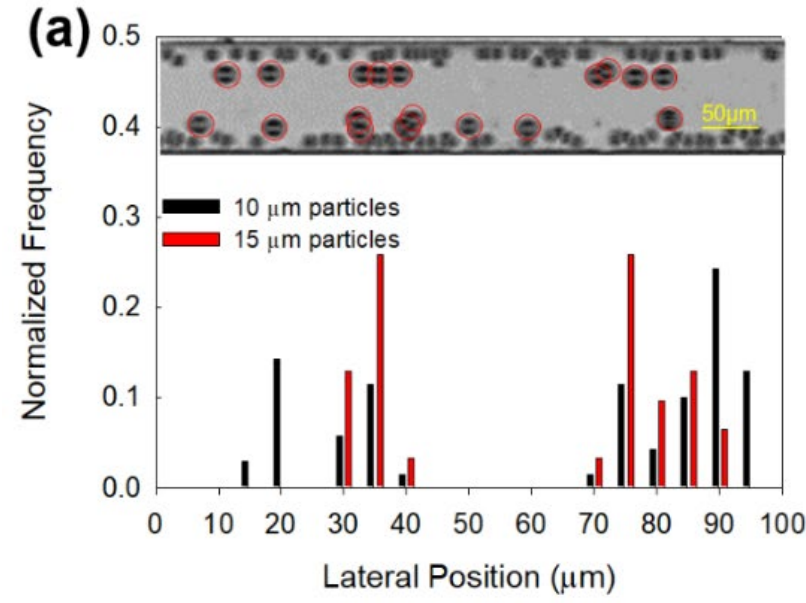

(b)

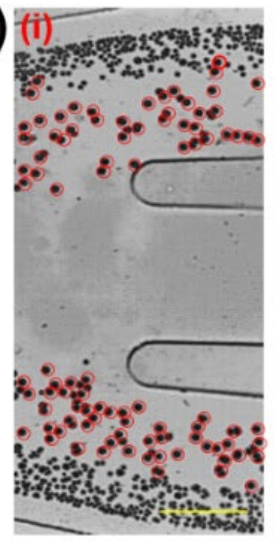

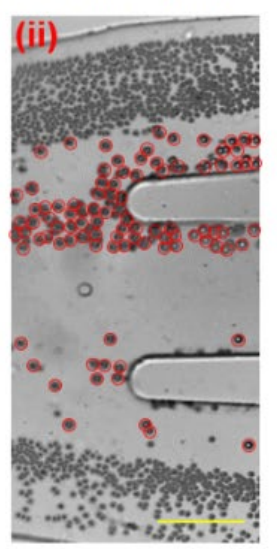

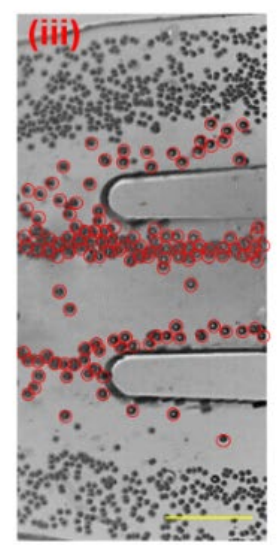

(c)

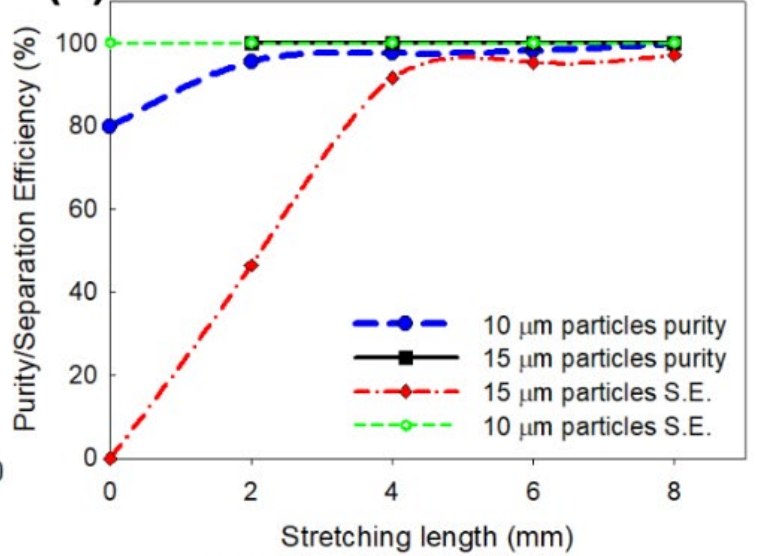

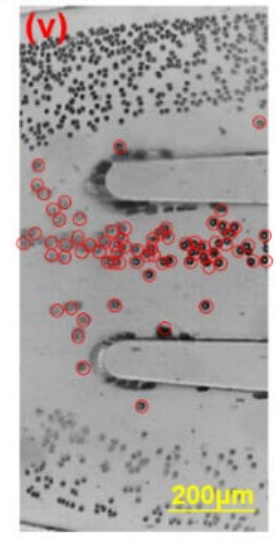

Figure 5. (a) Focusing positions of a mixture of $10-\mu \mathrm{m}$ and $15-\mu \mathrm{m}$ particles at the end of the straight channel without stretching. Both particles are not focused at the channel centre and located near the side walls. (b) Differential focusing behaviour of $10-\mu \mathrm{m}$ and $15-\mu \mathrm{m}$ particles at the expanding region of the channel outlet under different stretching lengths of (i) $0 \mathrm{~mm}$, (ii) $2 \mathrm{~mm}$ stretch, (iii) $4 \mathrm{~mm}$, (iv) $6 \mathrm{~mm}$, and (v) $8 \mathrm{~mm}$. The $15-\mu \mathrm{m}$ particles are indicated by red circles. (c) Separation purity and separation efficiency (S.E.) of $10-\mu \mathrm{m}$ and $15-\mu \mathrm{m}$ particles at increasing stretching lengths. The length of the straight channel is $5 \mathrm{~mm}$ and the flow ratio of sample to sheath fluid is $10 \mu \mathrm{l} / \mathrm{min}: 215 \mu \mathrm{l} / \mathrm{min}$.

\section{Channel length elongation under different flow rates}

In addition to the channel length, the flow rate of sample flow and sheath flow are the other critical parameters for particle separation in the proposed device. However, it is still unknown whether using a different flow rate will compromise or promote the performance of channel length elongation on particle separation. Here, we will examine the influence of stretching on particle separation under various flow rates.

First, we studied the effects of flow rates of sample flow and sheath flow on particle separation without any channel stretching. The detailed results of these experiments have been 
provided in SI, Figure S2. Next, we investigated particle separation by stretching the channel at different flow rates, and analysed particle separation performance (purity and S.E.) of the binary particle mixture, Figure 6 . We observed that by increasing the channel length, the separation efficiency (red dashed line) of $15-\mu \mathrm{m}$ particles increased up to $100 \%$ for each of the four different flow rates. This is because a longer channel provides more residence time as well as a higher migration speed for $15-\mu \mathrm{m}$ particles to reach the centre outlet. The purity of $15-\mu \mathrm{m}$ particles first remains constant and then declines rapidly when the stretching length reaches a threshold. Furthermore, the stretching length threshold is inversely proportional to the total flow rate. Increasing flow rate decreases the threshold of the stretching length. For example, if the total flow rate is 80 or $110 \mu \mathrm{l} / \mathrm{min}$, Figure $6(\mathrm{a}, \mathrm{b})$, the threshold of stretching length is about $4 \mathrm{~mm}$. However, if the total flow rate is $160 \mu 1 / \mathrm{min}$ or $210 \mu \mathrm{l} / \mathrm{min}$, Figure $6(\mathrm{c}, \mathrm{d})$, the threshold decreases to $2 \mathrm{~mm}$ and $0 \mathrm{~mm}$, respectively. This is because, at a higher flow rate, the large 15$\mu \mathrm{m}$ particles already arrive close to the channel centre before stretching and only a small amount of stretching is necessary to enable complete arrival of the particles at the channel centre. Stretching the channel beyond this threshold will cause the early arrival of a portion of the $10-\mu \mathrm{m}$ particles into the central area, consequently reducing the purity of $15-\mu \mathrm{m}$ particle collection.

The purity of $10-\mu \mathrm{m}$ particles increases with increasing stretching lengths and remain at around $100 \%$ after it reaches the peak value. In terms of the separation efficiency, the trend is similar to that of the purity of $15-\mu \mathrm{m}$ particles. The efficiency stays at its peak value for a specific range of stretching lengths and then decreases when the stretching length is beyond a threshold. The underlying mechanism is the same as above. When the device is stretched more than the threshold, some $10-\mu \mathrm{m}$ particles will arrive at the channel central outlet area, and the two-sided outlets lose a portion of of the $10-\mu \mathrm{m}$ particles, causing a reduced efficiency. Figure S3 illustrates how an optimum separation efficiency is achieved by stretching the device to a specific length while further elongation diminishes this balance and leads to lower purities and separation efficiencies. In conclusion, greater stretch does not always guarantee a better separation performance. The optimal stretching length depends highly on the flow rate, and a lower flow rate generally corresponds to a larger stretching length for optimal particle separation. We also compared the performance of the proposed device with that in the literature, as shown in Table S1. The superior advantage of our device is that it can be tuned on site not only by flow rates but also by channel stretching, which brings more flexibility and controllability on the separation process of particles with various sizes. 

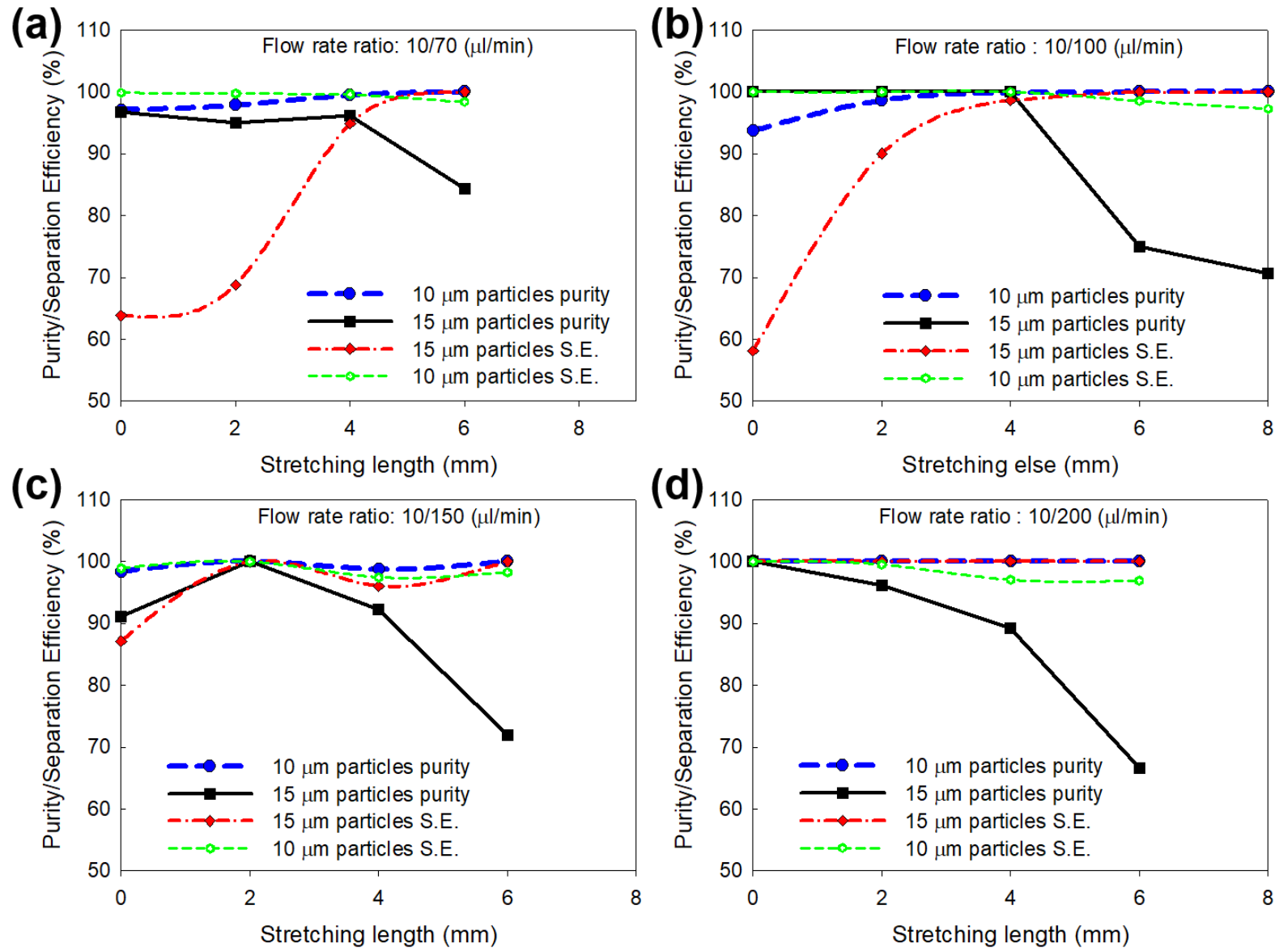

Figure 6. Purities and separation efficiencies (S.E.) of $10-\mu \mathrm{m}$ and $15-\mu \mathrm{m}$ particles under increasing channel stretching at different flow rate ratios of sample flow to sheath flow of (a) $10 \mu \mathrm{l} / \mathrm{min}: 70 \mu \mathrm{l} / \mathrm{min}$; (b) $10 \mu \mathrm{l} / \mathrm{min}: 100 \mu \mathrm{l} / \mathrm{min}$; (c) $10 \mu \mathrm{l} / \mathrm{min}: 150 \mu \mathrm{l} / \mathrm{min}$; and (d) $10 \mu \mathrm{l} / \mathrm{min}$ : $200 \mu 1 / \mathrm{min}$.

\section{CONCLUSIONS}

This paper reports on a stretchable inertial microfluidic device. This type of device can improve the focusing and separation of microparticles on site without the need for fabrication of a new device and without the need to reoptimise the operating conditions. We elongated a thin flexible microfluidic device along its length using a customised stretching platform. Once the channel was stretched along its length, the width and height of the channel shrank accordingly, which was confirmed by numerical simulation. It was shown through theoretical analysis that this longer channel length and shorter channel width allowed for improved particles focusing. We also demonstrated this experimentally, improving the focusing efficiency of particles from $28 \%$ to $100 \%$ after stretching. Furthermore, the separation efficiency for a binary mixture of $10-\mu \mathrm{m}$ and $15-\mu \mathrm{m}$ particles was improved significantly after stretching. We also analysed the efficiency of the device with different flow rate ratios and showed that if the flow rate ratio cannot lead to a desirable separation of particles, stretching the channel can improve focusing 
and separation efficiency to a high degree. This new research direction in the field of inertial microfluidics can be utilized to fabricate tunable devices for separation and sorting of bioparticles.

\section{ACKNOWLEDGMENTS}

Hedieh Fallahi acknowledges the support of the higher degree research scholarship from Griffith University. Jun Zhang greatly acknowledges the support from the National Natural Science Foundation of China (Grant No.51705257) and the Griffith University New Research Grant 2020. Nam-Trung Nguyen acknowledges the support from the Australian Research Council (ARC) Discovery Project (Grant No. DP180100055).

\section{ASSOCIATED CONTENT}

\section{Supporting Information}

(S-1) Design and fabrication of the stretchable microfluidic device; (S-2) Design and fabrication of the custom-made stretching platform; (S-3) Design guidelines for the straight channel; (S-4) COMSOL modelling; (S-5) Channel length optimisation under different flow rate ratios; (S-6) Particle inertial differential migration and separation mechanism in the straight channel; (S-7) Comparative assessment of separation performance of inertial devices; (Figure S1) Numerical simulation of the stretching process with COMSOL Multiphysics software; (Figure S2) Focusing positions of a mixture of $10-\mu \mathrm{m}$ and $15-\mu \mathrm{m}$ particles at the end of a 10-mm straight channel under different flow rate ratios (F.R.R.) of sample flow to sheath flow; (Figure S3) Distribution of $10-\mu \mathrm{m}$ and $15-\mu \mathrm{m}$ particles at the outlet expanding region under the stretching lengths of (a) $0 \mathrm{~mm}$, (b) $2 \mathrm{~mm}$, (c) $4 \mathrm{~mm}$, (d) $6 \mathrm{~mm}$, and (e) $8 \mathrm{~mm}$; (Figure S4) The differential inertial migration of particles in the rectangular channel with an aspect ratio of 0.5 ; (Table S1) Comparison of existing inertial microfluidic techniques for binaryparticle separation.

\section{AUTHOR INFORMATION}

\section{Author Contributions}

N.T.N. and J.Z. proposed and designed the project. H.F., H.P.P. and J.Z. designed and conducted the simulations. H.F. and J.Z. fabricated the experimental setup and test devices as well as conducted all the experimental work. J.Z. conducted the theoretical analysis. H.F., J.Z. and J.N. wrote the manuscript with the contribution from all other authors. All authors contributed to the interpretation of the results. 


\section{Notes}

The authors declare no competing financial interest.

\section{REFERENCES}

(1) Campos, E.; Branquinho, J.; Carreira, A. S.; Carvalho, A.; Coimbra, P.; Ferreira, P.; Gil, M. Designing polymeric microparticles for biomedical and industrial applications. European Polymer Journal 2013, 49, 2005-2021.

(2) Dickinson, E. Use of nanoparticles and microparticles in the formation and stabilization of food emulsions. Trends in Food Science \& Technology 2012, 24, 4-12.

(3) Metzger, T. S.; Tokatly, Y.; Avigad, E.; Yochelis, S.; Paltiel, Y. Selective enantiomer purification using magnetic oriented interacting microparticles. Separation and Purification Technology 2020, 239, 116501.

(4) Kozlowska, J.; Prus, W.; Stachowiak, N. Microparticles based on natural and synthetic polymers for cosmetic applications. International Journal of Biological Macromolecules 2019, $129,952-956$.

(5) Li, W.; Zhang, L.; Ge, X.; Xu, B.; Zhang, W.; Qu, L.; Choi, C.-H.; Xu, J.; Zhang, A.; Lee, H.; Weitz, D. A. Microfluidic fabrication of microparticles for biomedical applications. Chemical Society Reviews 2018, 47, 5646-5683.

(6) Zhou, R.; Bai, F.; Wang, C. Magnetic separation of microparticles by shape. Lab on a Chip 2017, 17, 401-406.

(7) Wu, Z.; Willing, B.; Bjerketorp, J.; Jansson, J. K.; Hjort, K. Soft inertial microfluidics for high throughput separation of bacteria from human blood cells. Lab on a Chip 2009, 9, 11931199.

(8) Wyatt Shields Iv, C.; Reyes, C. D.; López, G. P. Microfluidic cell sorting: a review of the advances in the separation of cells from debulking to rare cell isolation. Lab on a Chip 2015, $15,1230-1249$.

(9) Whitesides, G. M. The origins and the future of microfluidics. Nature 2006, 442, 368-373.

(10) Çetin, B.; Li, D. Dielectrophoresis in microfluidics technology. Electrophoresis 2011, 32, 2410-2427.

(11) Li, M.; Li, S.; Li, W.; Wen, W.; Alici, G. Continuous manipulation and separation of particles using combined obstacle-and curvature-induced direct current dielectrophoresis. Electrophoresis 2013, 34, 952-960.

(12) Forbes, T. P.; Forry, S. P. Microfluidic magnetophoretic separations of immunomagnetically labeled rare mammalian cells. Lab Chip 2012, 12, 1471-1479.

(13) Shen, F.; Hwang, H.; Hahn, Y. K.; Park, J. K. Label-Free Cell Separation Using a Tunable Magnetophoretic Repulsion Force. Analytical Chemistry 2012, 84, 3075-3081.

(14) Li, S.; Ding, X.; Guo, F.; Chen, Y.; Lapsley, M. I.; Lin, S.-C. S.; Wang, L.; McCoy, J. P.; Cameron, C. E.; Huang, T. J. An on-chip, multichannel droplet sorter using standing surface acoustic waves (SSAW). Analytical Chemistry 2013, 85, 5468-5474.

(15) Destgeer, G.; Lee, K. H.; Jung, J. H.; Alazzam, A.; Sung, H. J. Continuous separation of particles in a PDMS microfluidic channel via travelling surface acoustic waves (TSAW). Lab Chip 2013, 13, 4210-4216.

(16) MacDonald, M.; Spalding, G.; Dholakia, K. Microfluidic sorting in an optical lattice. Nature 2003, 426, 421-424.

(17) Jung, J. H.; Lee, K. H.; Lee, K. S.; Ha, B. H.; Oh, Y. S.; Sung, H. J. Optical separation of droplets on a microfluidic platform. Microfluid. Nanofluid. 2014, 16, 635-644.

(18) Ji, H. M.; Samper, V.; Chen, Y.; Heng, C. K.; Lim, T. M.; Yobas, L. Silicon-based microfilters for whole blood cell separation. Biomedical microdevices 2008, 10, 251-257. 
(19) Yamada, M.; Nakashima, M.; Seki, M. Pinched flow fractionation: continuous size separation of particles utilizing a laminar flow profile in a pinched microchannel. Anal. Chem. 2004, 76, 5465-5471.

(20) Huang, L. R.; Cox, E. C.; Austin, R. H.; Sturm, J. C. Continuous particle separation through deterministic lateral displacement. Science 2004, 304, 987-990.

(21) Choi, S.; Park, J. K. Continuous hydrophoretic separation and sizing of microparticles using slanted obstacles in a microchannel. Lab Chip 2007, 7, 890-897.

(22) Di Carlo, D. Inertial microfluidics. Lab Chip 2009, 9, 3038-3046.

(23) Zhang, J.; Yan, S.; Yuan, D.; Alici, G.; Nguyen, N.-T.; Ebrahimi Warkiani, M.; Li, W. Fundamentals and applications of inertial microfluidics: a review. Lab Chip 2016, 16, 10-34.

(24) Di Carlo, D.; Irimia, D.; Tompkins, R. G.; Toner, M. Continuous inertial focusing, ordering, and separation of particles in microchannels. Proc. Natl. Acad. Sci. U.S.A. 2007, 104, 18892-18897.

(25) Zhou, J.; Papautsky, I. Fundamentals of inertial focusing in microchannels. Lab Chip 2013, 13, 1121-1132.

(26) Tu, C.; Zhou, J.; Liang, Y.; Huang, B.; Fang, Y.; Liang, X.; Ye, X. A flexible cell concentrator using inertial focusing. Biomedical Microdevices 2017, 19, 83.

(27) Wang, X.; Papautsky, I. Size-based microfluidic multimodal microparticle sorter. Lab on a Chip 2015, 15, 1350-1359.

(28) Bogseth, A.; Zhou, J.; Papautsky, I. Evaluation of Performance and Tunability of a CoFlow Inertial Microfluidic Device. Micromachines 2020, 11, 287.

(29) Chung, A. J.; Gossett, D. R.; Di Carlo, D. Three Dimensional, Sheathless, and HighThroughput Microparticle Inertial Focusing Through Geometry-Induced Secondary Flows. Small 2013, 9, 685-690.

(30) Zhou, J.; Giridhar, P. V.; Kasper, S.; Papautsky, I. Modulation of aspect ratio for complete separation in an inertial microfluidic channel. Lab Chip 2013, 13, 1919-1929.

(31) Zhou, J.; Kulasinghe, A.; Bogseth, A.; O’Byrne, K.; Punyadeera, C.; Papautsky, I. Isolation of circulating tumor cells in non-small-cell-lung-cancer patients using a multi-flow microfluidic channel. Microsyst. Nanoeng. 2019, 5, 8 .

(32) Zhou, J.; Papautsky, I. Size-dependent enrichment of leukocytes from undiluted whole blood using shear-induced diffusion. Lab on a Chip 2019, 19, 3416-3426.

(33) Zhou, J.; Tu, C.; Liang, Y.; Huang, B.; Fang, Y.; Liang, X.; Papautsky, I.; Ye, X. Isolation of cells from whole blood using shear-induced diffusion. Scientific Reports 2018, 8, 9411.

(34) Zhou, J.; Tu, C.; Liang, Y.; Huang, B.; Fang, Y.; Liang, X.; Papautsky, I.; Ye, X. Microfluidic separation of particles from whole blood using shear induced diffusion; SPIE, 2017; Vol. 10061.

(35) Wang, X.; Yang, X.; Papautsky, I. An integrated inertial microfluidic vortex sorter for tunable sorting and purification of cells. TECHNOLOGY 2016, 04, 88-97.

(36) Mukherjee, P.; Wang, X.; Zhou, J.; Papautsky, I. Single stream inertial focusing in low aspect-ratio triangular microchannels. Lab on a Chip 2019, 19, 147-157.

(37) Zhang, J.; Yuan, D.; Zhao, Q.; Yan, S.; Tang, S.-Y.; Tan, S. H.; Guo, J.; Xia, H.; Nguyen, N.-T.; Li, W. Tunable particle separation in a hybrid dielectrophoresis (DEP)- inertial microfluidic device. Sensors and Actuators B: Chemical 2018, 267, 14-25.

(38) Zhou, Y.; Ma, Z.; Ai, Y. Dynamically tunable elasto-inertial particle focusing and sorting in microfluidics. Lab on a Chip 2020, 20, 568-581.

(39) Fallahi, H.; Zhang, J.; Phan, H.-P.; Nguyen, N.-T. Flexible Microfluidics: Fundamentals, Recent Developments, and Applications. Micromachines 2019, 10, 830.

(40) Segre, G. Radial particle displacements in Poiseuille flow of suspensions. Nature 1961, $189,209-210$. 
(41) Segre, G.; Silberberg, A. Behaviour of macroscopic rigid spheres in Poiseuille flow Part 2. Experimental results and interpretation. J. Fluid Mech. 1962, 14, 136-157.

(42) ASMOLOV, E. S. The inertial lift on a spherical particle in a plane Poiseuille flow at large channel Reynolds number. J. Fluid Mech. 1999, 381, 63-87.

(43) Chung, A. J.; Gossett, D. R.; Di, C. D. Three dimensional, sheathless, and high-throughput microparticle inertial focusing through geometry-induced secondary flows. Small 2013, 9, 685690.

(44) Gossett, D. R.; Weaver, W. M.; Mach, A. J.; Hur, S. C.; Tse, H. T. K.; Lee, W.; Amini, H.; Di Carlo, D. Label-free cell separation and sorting in microfluidic systems. Anal. Bioanal. Chem. 2010, 397, 3249-3267.

(45) Zhang, J.; Yan, S.; Sluyter, R.; Li, W.; Alici, G.; Nguyen, N.-T. Inertial particle separation by differential equilibrium positions in a symmetrical serpentine micro-channel. Sci. Rep. 2014, 4, Art No. 4527. 


\section{Supporting Information}

\section{A stretchable inertial microfluidic device for tunable particle separation}

Hedieh Fallahi, Jun Zhang, Jordan Nicholls, Hoang-Phuong Phan and Nam-Trung Nguyen *

Queensland Micro and Nanotechnology Centre, Griffith University, Brisbane, QLD 4111, Australia

* Correspondence: nam-trung.nguyen@griffith.edu.au; Tel: +61-(07)-3735-3921; Fax: +61(07)-3735-80211;

\section{Table of contents}

S-1 Design and fabrication of the stretchable microfluidic device

S-2 Design and fabrication of the custom-made stretching platform

S-3 Design guidelines for the straight channel

S-4 COMSOL modelling

S-5 Channel length optimisation under different flowrate ratios

S-6 Particle inertial differential migration and separation mechanism in the straight channel

S-7 Comparative assessment of separation performance of inertial devices

Figure S1. Numerical simulation of the stretching process with COMSOL Multiphysics software:

Figure S2. Focusing positions of a mixture of $10-\mu \mathrm{m}$ and $15-\mu \mathrm{m}$ particles at the end of a 10$\mathrm{mm}$ straight channel under different flow rate ratios (F.R.R.) of sample flow to sheath flow.

Figure S3. Distribution of $10-\mu \mathrm{m}$ and $15-\mu \mathrm{m}$ particles at the outlet expanding region under the stretching lengths of (a) $0 \mathrm{~mm}$, (b) $2 \mathrm{~mm}$, (c) $4 \mathrm{~mm}$, (d) $6 \mathrm{~mm}$, and (e) $8 \mathrm{~mm}$.

Figure S4. The differential inertial migration of particles in the rectangular channel with an aspect ratio of 0.5 .

Table S1. Comparison of existing inertial microfluidic techniques for binary-particle separation. 


\section{S-1 Design and fabrication of the stretchable microfluidic device}

The stretchable microfluidic devices were fabricated with standard photolithography and soft lithography, Figure 2(a). First, a negative photoresist (SU-8 3050, MicroChem Corp.) was spread on a 4-inch silicon wafer by spin coating, and then selectively exposed to UV light through a photomask. After development, the unexposed photoresist was removed, and the remaining SU8/silicon master was used for the replication of the polydimethylsiloxane (PDMS) device (i). Next, Sylgard 184 prepolymer (Sylgard 184, Dow Corning) and the corresponding curing agent were mixed in a ratio of 10:1 of elastomer base to the curing agent. The liquid solution was cast onto the silicon master with a thickness of $500 \mu \mathrm{m}$. After curing in an oven at $75^{\circ} \mathrm{C}$ for 2 hours, the thin channel layer was peeled off the mask (ii) and then bonded onto two thick PDMS slabs (5 mm thickness) located on the top side of the inlet and outlet (iii). The inlet and outlet holes were punched through the PDMS slabs (iv) to hold the tubing for the delivery of particle sample and collection of separated particles. Subsequently, another $500-\mu \mathrm{m}$ thin PDMS layer (iv) was bonded to the channel layer and sealed the microchannels (v). Finally, two 1-mm thick PDMS slabs (v) were bonded to the channel layer at the opposite side but the same position as the top PDMS slabs (vi) to add structural support to the undersides of the inlet and outlet. This structural enforcement prevents the channels from collapsing and becoming blocked when the whole device was clamped on the stretching platform. Figure 2(b) shows the fabricated stretchable PDMS microfluidic device.

\section{S-2 Design and fabrication of the custom-made stretching platform}

A custom- made stretching platform was designed and fabricated as illustrated in Figure 2 (c). The stretching platform consists of a micrometre translation stage (i) mounted on top of a poly (methyl methacrylate) (PMMA) holder (ii). Two metal clamps (iii) that were screwed to two PMMA slabs (iv) are then attached to either side of the translation stage to hold the microfluidic device (v). The shape of the clamping slabs was optimised to minimise the impact on the fluid flow and not to obscure the view of the microchannels under the microscope. Since the inlet and outlet sections of the microfluidic device are much thicker than the channel section and are tightly secured with the clamps, the deformation is mostly confined to the channel section, with negligible deformation of the inlet and outlet regions. Figure 2(d) shows the image of a flexible PDMS device clamped in the stretching platform. The inset shows a photo of the PDMS microfluidic device under elongation. 


\section{S-3 Design guidelines for the straight channel}

For a straight channel, the lateral migration velocity of particles $U_{\mathrm{L}}$ is expressed in the Equation (5) and repeated here:

$$
U_{L}=\frac{F_{L}}{3 \pi \mu a}=\frac{4 U_{f}^{2} \rho a^{3} f_{L}}{3 \pi \mu D_{h}^{2}}
$$

The channel length $L_{c}$ that particles reached the complete focusing, i.e., all particles arrive at the channel centre can be estimated as ${ }^{1}$ :

$$
L_{c}=\frac{W U_{f}}{U_{L}}=\frac{3 W \pi \mu D_{h}^{2}}{4 U_{f} \rho a^{3} f_{L}}
$$

According to the experimental data from Zhou and Papautsky ${ }^{1}$, the average $f_{L}$ ranges from $\sim 0.005$ to $\sim 0.065$.

For separation of binary particles with diameters of $a_{1}$ and $a_{2}$. Assuming $\mathrm{a}_{1}>\mathrm{a}_{2}$, after travelling through a straight channel with a length of $L$, the lateral distance difference of binary particles is:

$$
\left(L_{D 1}-L_{D 2}\right)=\left(U_{L 1}-U_{L 2}\right) \frac{L}{2 U_{f}}=\frac{2 U_{f} \rho L f_{L}}{3 \pi \mu D_{h}^{2}}\left(a_{1}^{2}-a_{2}^{2}\right)
$$

This equation is valid when the large particles have not or just arrived at the channel centre at the end of the channel, i.e. $\mathrm{L} \leq \mathrm{L}_{\mathrm{c} 1}$.

Based on the equations (S2, S3), we can estimate the channel length needed for focusing of specific particles and estimate the lateral distance of binary particles. The determination of channel length is a rough estimation and this value may not be able to focus particle completely. Fortunately, the stretchable device proposed in this work can adjust channel length further nosite to optimise the particle focusing and separation. This is the intrinsic advantages of the stretchable inertial microfluidic device.

\section{S-4 COMSOL modelling}

We used COMSOL Multiphysics v5.4 to gain further insight into how the dimensions of the microchannel change under stretching. Our stretchable microfluidic device has been designed so that only the device section with the microchannel undergoes stretching, while the inlet and outlet sections remain without deformation. Under stretching, the length of the channels increases while the width and the height decrease. A three-dimensional model with a 10-mm long microchannel resembling the actual device was then analysed. PDMS as a viscoelastic material with its default properties in COMSOL was defined to the model. The simulations 
with $\sim 16,000$ and $\sim 107,000$ finite elements contributed to the same results. Figure S1(a) shows the typical results using an extremely fine mesh ( 107,000 finite elements).

Figure S1(b)i to iv illustrate the simulation results for four stretching lengths $(2,4,6$, and $8 \mathrm{~mm}$ ). The colours indicate the stress applied on the surfaces of the microfluidic device. The dark blue colour at the inlet and outlet areas indicates zero stress, which matches with the clamming condition in our experimental setup. The stress due to stretching distributes along the flexible channel section of the device, with some stress concentration at the edges of the channel.

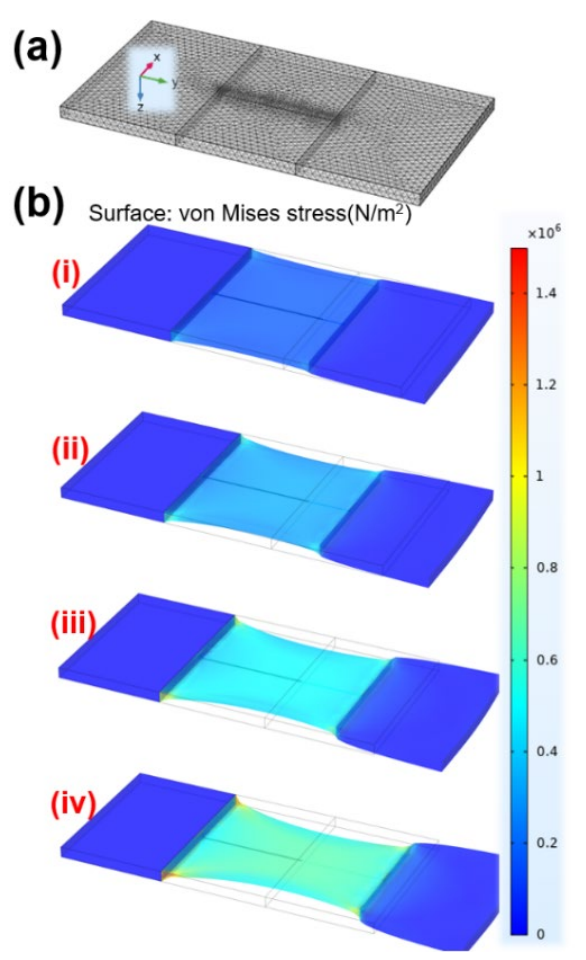

Figure S1. Numerical simulation of the stretching process with COMSOL Multiphysics software: (a) The geometry of the device with extremely fine meshing; (b) The device after being stretched 2 (i), 4 (ii), 6 (iii), and $8 \mathrm{~mm}$ (iv) along its length (y direction). The colours indicate the stress values.

\section{S-5 Channel length optimisation under different flowrate ratios}

\section{(i) Effect of flowrate ratio on particle separation at 0 stretch}

We studied the effects of flow rates of sample flow and sheath flow on particle separation without any channel stretching. We kept the sample flow rate constant at $10 \mu 1 / \mathrm{min}$, and varied the sheath flow rate from $70 \mu \mathrm{l} / \mathrm{min}$ to $200 \mu \mathrm{l} / \mathrm{min}$, so that the total flow rate varied from $80 \mu \mathrm{l} / \mathrm{min}$ to $210 \mu \mathrm{l} / \mathrm{min}$ and the corresponding flow rate ratio of sample flow to sheath flow varying from 1:7 to $1: 20$. If the sheath flow rate is more than 7 times the sample flow rate, all particles from the sample flow are tightly pinched to the sidewalls, thus the total flow rate becomes the key factor affecting the particle lateral migration and separation. A mixture of 10- 
$\mu \mathrm{m}$ and $15-\mu \mathrm{m}$ particles as the sample flow was introduced into a $10-\mathrm{mm}$ long channel. The distribution of particles at the end of the straight channel was captured and analysed, Figure S2. Increasing the total flow rate increases the number of large $15-\mu \mathrm{m}$ particles arriving at the channel centre. The smaller $10-\mu \mathrm{m}$ particles remain mostly along the two sidewalls. As such, the separation boundary between the $15-\mu \mathrm{m}$ and the $10-\mu \mathrm{m}$ particles becomes increasingly distinct when the total flow rate increases, Figure S2.
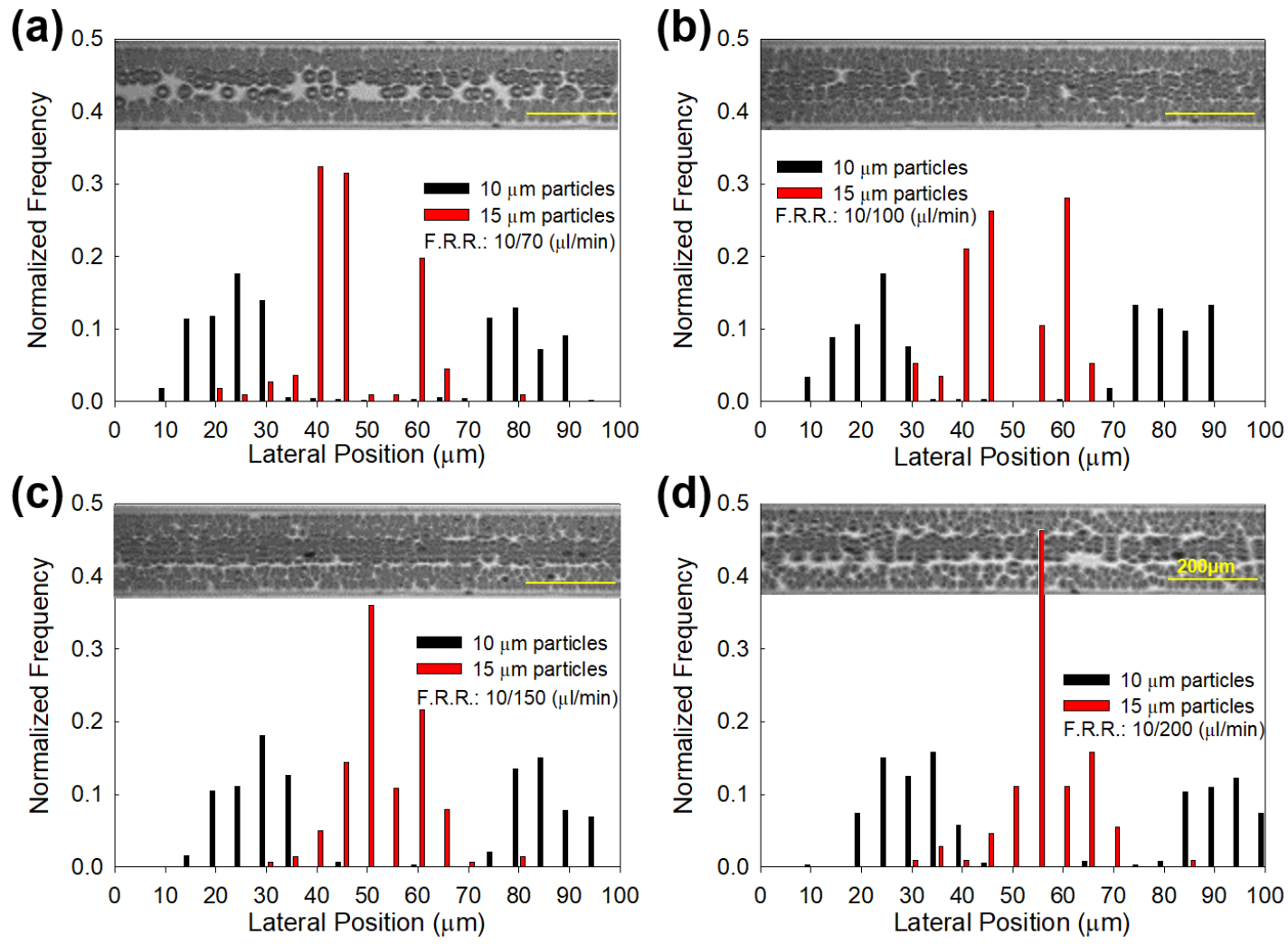

Figure S2. Focusing positions of a mixture of $10-\mu \mathrm{m}$ and $15-\mu \mathrm{m}$ particles at the end of a $10-$ $\mathrm{mm}$ straight channel under different flow rate ratios (F.R.R.) of sample flow to sheath flow of (a) $10 \mu \mathrm{l} / \mathrm{min}: 70 \mu \mathrm{l} / \mathrm{min} ;$ (b) $10 \mu \mathrm{l} / \mathrm{min}: 100 \mu \mathrm{l} / \mathrm{min}$; (c) $10 \mu \mathrm{l} / \mathrm{min}: 150 \mu \mathrm{l} / \mathrm{min}$; and (d) $10 \mu \mathrm{l} / \mathrm{min}: 200 \mu \mathrm{l} / \mathrm{min}$.

\section{(2) Effect of flowrate ratio on particle separation under stretch}

A binary mixture of $10-\mu \mathrm{m}$ and $15-\mu \mathrm{m}$ particles were introduced to the device with a sample to sheath flow rate ratio of 10/100. As illustrated in Figure S3., by stretching the channel length to $4 \mathrm{~mm}$, focusing and separation efficiency improves. However, further stretching the channel length focuses the 10-um particles to the centre which reduces the purity and separation efficiency of $15-\mu \mathrm{m}$ particles. 

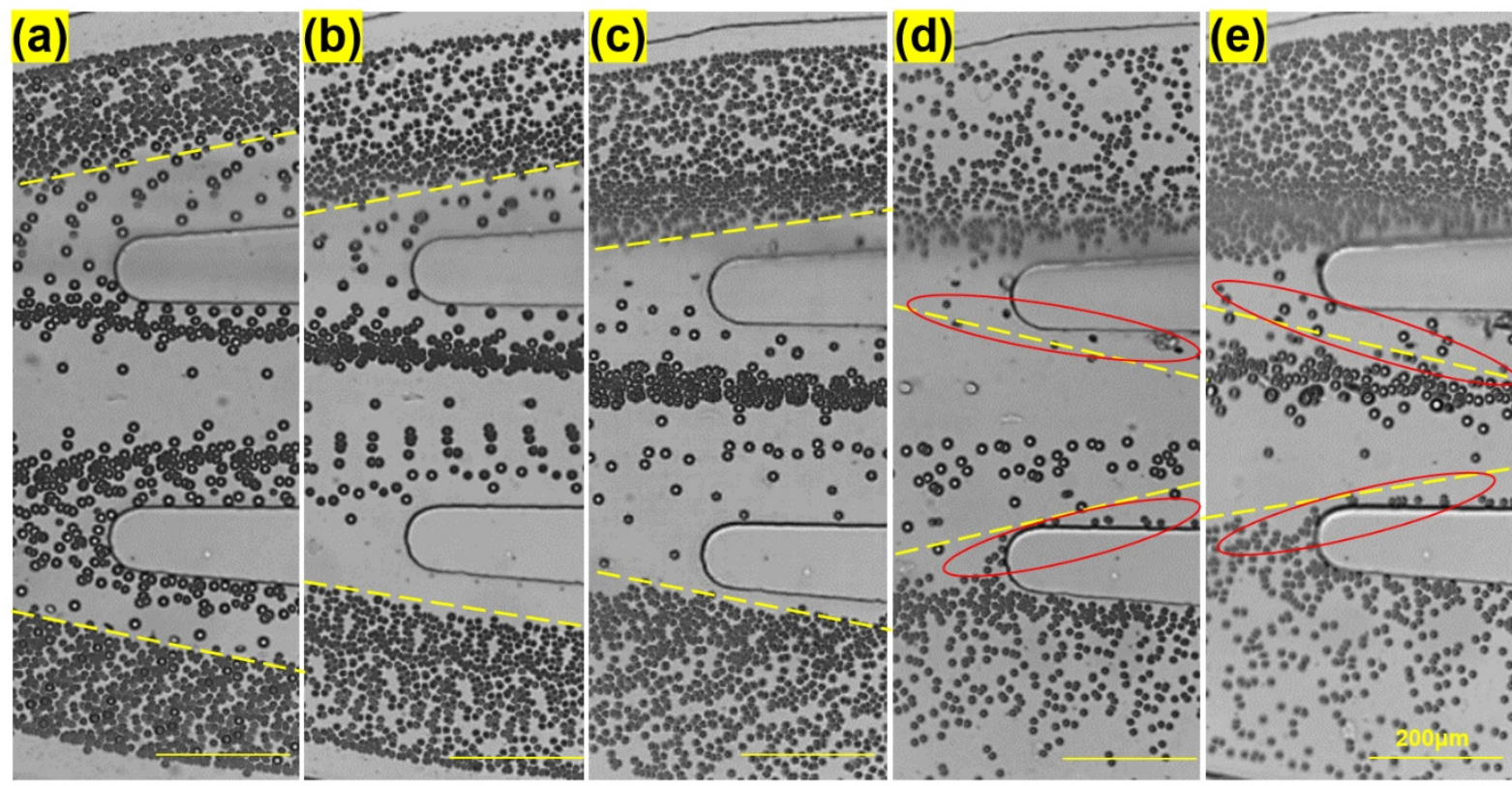

Figure S3. Distribution of $10-\mu \mathrm{m}$ and $15-\mu \mathrm{m}$ particles at the outlet expanding region under the stretching lengths of (a) $0 \mathrm{~mm}$, (b) $2 \mathrm{~mm}$, (c) $4 \mathrm{~mm}$, (d) $6 \mathrm{~mm}$, and (e) $8 \mathrm{~mm}$. Yellow dashed lines indicate the boundary between the $10-\mu \mathrm{m}$ and $15-\mu \mathrm{m}$ particles. The boundary moves toward the channel centre with an increasing stretching length. However, when the stretching length is over $6 \mathrm{~mm}$, the boundary is within the central outlet. In this case, some small $10-\mu \mathrm{m}$ particles can get into the central outlet, deteriorating the purity of $15-\mu \mathrm{m}$ particles as well as the separation efficiency of $10-\mu \mathrm{m}$ particles. Here, the flow rate ratio of the particle sample to sheath flow is $10 \mu \mathrm{l} / \mathrm{min}: 100 \mu \mathrm{l} / \mathrm{min}$.

\section{S-6 Particle inertial differential migration and separation mechanism in the straight channel}

The migration of particles in the rectangular channel with an aspect ratio of 0.5 was explained by the two-stage migration theory ${ }^{1}$. At first, particles migrate and equilibrate near the top and bottom walls. This happens due to the shear force $\left(\mathrm{F}_{\mathrm{S}}\right)$ pushes particles toward the top and bottom walls, and eventually be balanced by the wall-induced force $\left(\mathrm{F}_{\mathrm{W}}\right)$. After that, the rotation-induced lift force dominates the motion of particles and pushes them to the channel centre. Furthermore, the magnitude of the rotation induced lift force $\left(\mathrm{F}_{\Omega}\right)$ is highly dependent on particles size, particles with a greater size can migrate faster than the small ones, therefore, particles with different sizes can be separated, as shown in Figure S4. 

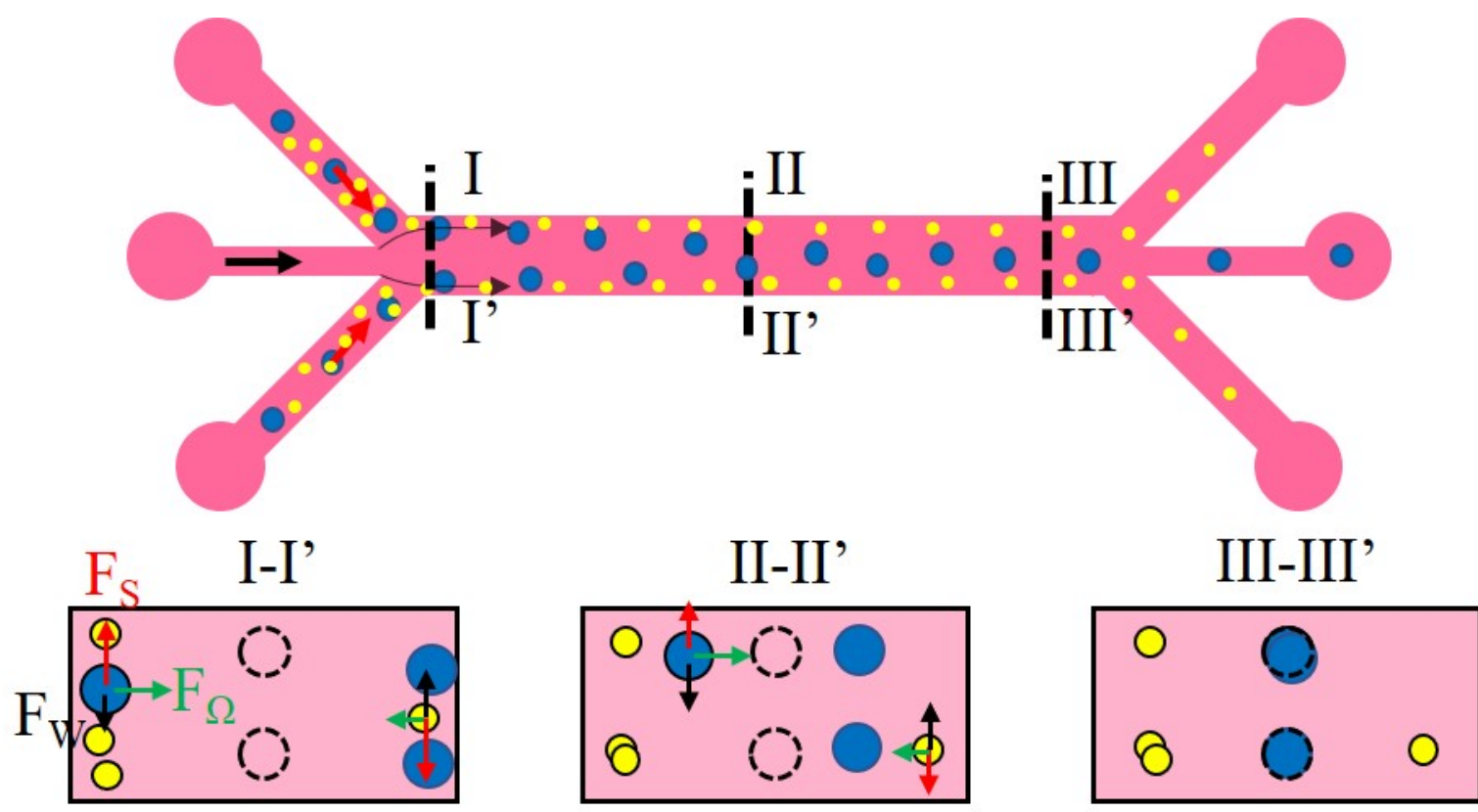

Figure S4. The differential inertial migration of particles in the rectangular channel with an aspect ratio of 0.5 . The migration of particles is controlled by the shear-induced $\left(F_{S}\right)$, wallinduced $\left(\mathrm{F}_{\mathrm{W}}\right)$ and rotation-induced $\left(\mathrm{F}_{\Omega}\right)$ forces. The dashed circle indicates the final equilibrium positions of particles.

\section{S-7 Comparative assessment of separation performance of inertial devices}

By having a stretchable microfluidic device that can tune its dimensions onsite, we can obtain high degrees of S.E and purity at any flow conditions which was not feasible with other inertial microfluidic devices. A comparative assessment of the separation performance of our device relative to other devices in the literature has been provided in Table S1.

Table S1. Comparison of existing inertial microfluidic techniques for binary-particle separation.

\begin{tabular}{|c|c|c|c|c|c|c|c|c|}
\hline $\begin{array}{c}\text { Channel } \\
\text { Type }\end{array}$ & $\begin{array}{c}\text { Flow rate/ } \\
\text { throughp } \\
\text { ut }\end{array}$ & Purity & Efficiency & $\begin{array}{c}\text { Channel } \\
\text { dimension }\end{array}$ & Particle size & $\begin{array}{c}\text { Size } \\
\text { difference } \\
\text { (Resolutio } \\
\text { n) } \\
\end{array}$ & $\begin{array}{c}\text { On site } \\
\text { tunability }\end{array}$ & $\begin{array}{c}\text { Refere } \\
\text { nce }\end{array}$ \\
\hline \multirow[t]{2}{*}{ Straight } & $\begin{array}{c}\mathrm{Re}=40 \\
(100 \mu \mathrm{lm} \\
\text { in-1) }\end{array}$ & $\begin{array}{c}20-\mu \mathrm{m} \\
\text { particle } \\
90.8 \% \\
9.94-\mu \mathrm{m} \\
99.6 \%\end{array}$ & $\begin{array}{c}20-\mu \mathrm{m} \\
\text { particle } \\
99.3 \% \\
9.94-\mu \mathrm{m} \\
94.5 \%\end{array}$ & $\begin{array}{c}27 \mu \mathrm{m} \times 50 \mu \\
\mathrm{m} \& \\
100 \mu \mathrm{m} \times 50 \\
\mu \mathrm{m}\end{array}$ & $\begin{array}{c}9.9-\mu \mathrm{m} \\
20-\mu \mathrm{m}\end{array}$ & $\sim 10 \mu \mathrm{m}$ & Flow rate & 2 \\
\hline & $\begin{array}{c}40 \\
\text { channels } \\
: \\
240 \mathrm{ml} / \mathrm{h}, \\
4 \times 10^{8} \\
\text { cells } / \mathrm{mi} \\
\mathrm{n}\end{array}$ & NA & $\begin{array}{c}88 \% \text { red } \\
\text { blood } \\
\text { cells } \\
\text { (RBCs) } \\
\text { E Coli: } \\
\text { NA }\end{array}$ & $\begin{array}{c}20 \mu \mathrm{m} \times 60 \mu \\
\mathrm{m} \\
\text { upstream } \\
160 \mu \mathrm{m} \times 60 \\
\mu \mathrm{m} \\
\text { downstrea } \\
\mathrm{m}\end{array}$ & $\begin{array}{c}\text { RBCs } \sim 8 \mu \mathrm{m} \\
\text { Eschericha } \\
\text { coli } \sim 1 \mu \mathrm{m}\end{array}$ & $\sim 7 \mu \mathrm{m}$ & Flow rate & 3 \\
\hline $\begin{array}{l}\text { Straight } \\
\text { - Co- }\end{array}$ & $\begin{array}{l}\text { Sample: } \\
0.3 \mathrm{ml} / \mathrm{h}\end{array}$ & $90 \%<$ & $90 \%<$ & $\begin{array}{c}\mathrm{H} \times \mathrm{W} \times \mathrm{L} \\
(50 \mu \mathrm{m}, 20\end{array}$ & 1 and $2 \mu \mathrm{m}$ & $\sim 1 \mu \mathrm{m}$ & Flow rate & 4 \\
\hline
\end{tabular}




\begin{tabular}{|c|c|c|c|c|c|c|c|c|}
\hline $\begin{array}{l}\text { flow, } \\
\text { viscoela } \\
\text { stic } \\
\text { buffer }\end{array}$ & $\begin{array}{c}\text { Buffer: } \\
1.2-3 \\
\mathrm{ml} / \mathrm{h}\end{array}$ & & & $\begin{array}{c}\mu \mathrm{m}, 15 \\
\mathrm{~mm})\end{array}$ & & & & \\
\hline \multirow[t]{2}{*}{$\begin{array}{l}\text { Expansi } \\
\text { on- } \\
\text { contract } \\
\text { ion } \\
\text { array }\end{array}$} & $\begin{array}{c}111 \\
\text { beads/s }\end{array}$ & $\begin{array}{c}10-\mu \mathrm{m} \\
\text { particle } \\
100 \% \\
4-\mu \mathrm{m} \\
\text { particle } \\
99 \%\end{array}$ & NA & $\begin{array}{c}\text { CEA } \\
350 \mu \mathrm{m} \\
\times 38 \mu \mathrm{m} \\
\& 50 \mu \mathrm{m} \\
\times 300 \mu \mathrm{m}\end{array}$ & $4-\mu \mathrm{m}, 10-\mu \mathrm{m}$ & $6 \mu \mathrm{m}$ & Flow rate & 5 \\
\hline & $\begin{array}{c}1.1 \times 10^{8} \\
\text { cells } / \mathrm{mi} \\
\mathrm{n} \\
\mathrm{Re}=8\end{array}$ & $\begin{array}{l}\text { Blood } \\
\text { cell } \\
\text { reject } \\
\text { ratio } \\
88.9 \%\end{array}$ & $\begin{array}{l}\text { Cancer } \\
\text { cells: } \\
99.1 \%\end{array}$ & $\begin{array}{c}350 \mu \mathrm{m} \\
\times 63 \mu \mathrm{m} \& \\
50 \mu \mathrm{m} \\
\times 1200 \mu \mathrm{m}\end{array}$ & $\begin{array}{c}\text { MCF-7, } \\
\text { blood cells }\end{array}$ & NA & Flow rate & 6 \\
\hline \multirow[t]{2}{*}{ Spiral } & $3 \mathrm{ml} / \mathrm{hr}$ & NA & $\begin{array}{c}\text { Cancer } \\
\text { cells }>85 \\
\%\end{array}$ & $\begin{array}{c}500 \mu \mathrm{m} \times 16 \\
0 \mu \mathrm{m}\end{array}$ & $\begin{array}{c}\text { MCF-7, } \\
\text { Hela, } \\
\text { MDA-MB- } \\
231 \\
\end{array}$ & NA & Flow rate & 7 \\
\hline & $\begin{array}{c}7.5 \mathrm{ml} \\
\text { blood } \\
\text { within } 8 \\
\text { mins }\end{array}$ & NA & $\begin{array}{c}>80 \% \\
\text { Blood } \\
\text { cells:NA }\end{array}$ & $\begin{array}{c}\text { Width } 100 \\
\mu \mathrm{m} \\
\text { Inner/outer } \\
80 \mu / 130 \mu \\
\mathrm{m} \\
\end{array}$ & $\begin{array}{c}\text { T24, MVF- } \\
7, \\
\text { MDA-MB- } \\
231\end{array}$ & NA & Flow rate & 8 \\
\hline $\begin{array}{c}\text { Double } \\
\text { spiral }\end{array}$ & $\begin{array}{c}3.33 \\
\times 10^{7} \\
\text { cells } / \mathrm{mi} \\
\mathrm{n}\end{array}$ & NA & $\begin{array}{c}99.66 \%: \\
92.75 \%: \\
88.5 \%\end{array}$ & $\begin{array}{c}300 \mu \mathrm{m} \text { in } \\
\times 50 \mu \mathrm{m} \text { in } \\
\text { height } \\
\text { Curvature } \\
\text { radius } 9 \\
\text { mm }\end{array}$ & $\begin{array}{l}5-\mu \mathrm{m}, 15-\mu \mathrm{m} \\
\text { polystyrene } \\
\text { beads } \\
\text { MCF-7 and } \\
\text { Hela cells }\end{array}$ & $10 \mu \mathrm{m}$ & Flow rate & 9 \\
\hline $\begin{array}{l}\text { Asymm } \\
\text { etric } \\
\text { serpenti } \\
\text { ne }\end{array}$ & $\begin{array}{c}0.9 \\
\mathrm{ml} / \mathrm{min}\end{array}$ & $\begin{array}{c}9-\mu \mathrm{m} \\
\text { particle: } \\
16.3 \% \\
\text { one tier, } \\
25.3 \% \\
3.1-\mu \mathrm{m} \\
\text { particle: } \\
\sim 99.9 \%\end{array}$ & $\begin{array}{l}3.1-\mu \mathrm{m}: \\
\sim 56 \% \\
\text { after two } \\
\text { tiers; } \\
9-\mu \mathrm{m}: \mathrm{NA}\end{array}$ & $\begin{array}{l}100 \sim 650 \mu \\
\mathrm{m} \times 50 \mu \mathrm{m}\end{array}$ & $\begin{array}{c}3.1 \text { and 9- } \\
\mu \mathrm{m}\end{array}$ & $\sim 6 \mu \mathrm{m}$ & Flow rate & 10 \\
\hline $\begin{array}{l}\text { Symmet } \\
\text { ric } \\
\text { serpenti } \\
\text { ne }\end{array}$ & $1 \mathrm{ml} / \mathrm{min}$ & $\begin{array}{c}10-\mu \mathrm{m}: \\
99.21 \% \\
15-\mu \mathrm{m}: \\
84 \%\end{array}$ & NA & $\begin{array}{c}\text { Width: } 200 \\
\mu \mathrm{m}-300 \\
\mu \mathrm{m} \\
\times 50 \mu \mathrm{m}- \\
110 \mu \mathrm{m} \\
\end{array}$ & $\begin{array}{l}10 \mu \mathrm{m} \\
15 \mu \mathrm{m}\end{array}$ & $\sim 5 \mu \mathrm{m}$ & Flow rate & 11 \\
\hline $\begin{array}{c}\text { The } \\
\text { stretcha } \\
\text { ble } \\
\text { device } \\
\text { in the } \\
\text { current } \\
\text { work }\end{array}$ & $\begin{array}{c}\text { Sample: } \\
10 \\
\mu 1 / \mathrm{min} \\
\text { Buffer: } \\
50,70,10 \\
0,150,20 \\
0 \mu 1 / \mathrm{min}\end{array}$ & $\begin{array}{c}10-\mu \mathrm{m}: \\
95- \\
100 \% \\
15-\mu \mathrm{m}: \\
95- \\
100 \%\end{array}$ & $\begin{array}{c}10-\mu \mathrm{m}: \\
98- \\
100 \% \\
15-\mu \mathrm{m}: \\
97- \\
100 \%\end{array}$ & $\begin{array}{l}100 \mu \mathrm{m} \\
\times 50 \mu \mathrm{m}\end{array}$ & $\begin{array}{l}10 \mu \mathrm{m} \\
15 \mu \mathrm{m}\end{array}$ & $\sim 5 \mu \mathrm{m}$ & $\begin{array}{l}\text { Flow } \\
\text { rate; } \\
\text { Stretchin } \\
\text { g along } \\
\text { channel } \\
\text { length }\end{array}$ & $\begin{array}{l}\text { This } \\
\text { work }\end{array}$ \\
\hline
\end{tabular}

\section{References}

(1) Zhou, J.; Papautsky, I. Fundamentals of inertial focusing in microchannels. Lab Chip 2013, 13, 1121-1132.

(2) Zhou, J.; Giridhar, P. V.; Kasper, S.; Papautsky, I. Modulation of aspect ratio for complete separation in an inertial microfluidic channel. Lab Chip 2013, 13, 1919-1929. 
(3) Mach, A. J.; Di Carlo, D. Continuous scalable blood filtration device using inertial microfluidics. Biotechnol. Bioeng. 2010, 107, 302-311.

(4) Tian, F.; Zhang, W.; Cai, L.; Li, S.; Hu, G.; Cong, Y.; Liu, C.; Li, T.; Sun, J. Microfluidic co-flow of Newtonian and viscoelastic fluids for high-resolution separation of microparticles. Lab on a Chip 2017, 17, 3078-3085.

(5) Lee, M. G.; Choi, S.; Park, J. K. Inertial separation in a contraction-expansion array microchannel. J. Chromatogr. A 2011, 1218, 4138-4143.

(6) Lee, M. G.; Shin, J. H.; Bae, C. Y.; Choi, S.; Park, J.-K. Label-free cancer cell separation from human whole blood using inertial microfluidics at low shear stress. Anal. Chem. 2013, $85,6213-6218$.

(7) Hou, H. W.; Warkiani, M. E.; Khoo, B. L.; Li, Z. R.; Soo, R. A.; Tan, D. S.-W.; Lim, W.T.; Han, J.; Bhagat, A. A. S.; Lim, C. T. Isolation and retrieval of circulating tumor cells using centrifugal forces. Scientific reports $\mathbf{2 0 1 3}, 3,1259$.

(8) Warkiani, M. E.; Guan, G.; Luan, K. B.; Lee, W. C.; Bhagat, A. A. S.; Chaudhuri, P. K.; Tan, D. S.-W.; Lim, W. T.; Lee, S. C.; Chen, P. C. Slanted spiral microfluidics for the ultrafast, label-free isolation of circulating tumor cells. Lab Chip 2014, 14, 128-137.

(9) Sun, J.; Li, M.; Liu, C.; Zhang, Y.; Liu, D.; Liu, W.; Hu, G.; Jiang, X. Double spiral microchannel for label-free tumor cell separation and enrichment. Lab Chip 2012, 12, 39523960.

(10) Di Carlo, D.; Edd, J. F.; Irimia, D.; Tompkins, R. G.; Toner, M. Equilibrium separation and filtration of particles using differential inertial focusing. Anal. Chem. 2008, 80, 2204-2211. (11) Zhang, J.; Yuan, D.; Zhao, Q.; Teo, A. J.; Yan, S.; Ooi, C. H.; Li, W.; Nguyen, N.-T. Fundamentals of differential particle inertial focusing in symmetric sinusoidal microchannels. Anal. Chem. 2019, 91, 4077-4084. 